\title{
Basic desert of reactive emotions
}

\author{
Zac Cogley* \\ Department of Philosophy, Northern Michigan University, Marquette, MI, USA
}

\begin{abstract}
In this paper, I explore the idea that someone can deserve resentment or other reactive emotions for what she does by attention to three psychological functions of such emotions - appraisal, communication, and sanction - that I argue ground claims of their desert. I argue that attention to these functions helps to elucidate the moral aims of reactive emotions and to distinguish the distinct claims of desert, as opposed to other moral considerations.
\end{abstract}

Keywords: desert; blame; resentment; emotions; anger; moral responsibility

\section{Introduction}

\subsection{Preliminaries}

It is commonly held that the most significant notion of moral responsibility in the free will debate is being deserving of blame or credit for actions we perform (Zimmerman 1988; Pereboom 2001; Bennett 2002; Strawson 2002; Sommers 2007; McKenna 2012). As Derk Pereboom puts it:

\begin{abstract}
this desert is basic in the sense that the agent would deserve the blame or credit just because he has performed the action, given understanding of its moral status, and not by virtue of consequentialist or contractual considerations. $(2008,168)$
\end{abstract}

While there are different views of exactly what blame is, one very prominent account identifies blame with emotions. Susan Wolf has recently defended such a view, saying that 'the paradigm of blame involves an "angry" feeling or attitude' (Wolf 2011, 344). Perhaps the fullest such account is R. Jay Wallace's (1994, 2011) examination of Strawson's (1982) reactive emotions, focusing on resentment, anger, and indignation. Pereboom appears to agree with Wolf and Wallace, saying 'of all the attitudes associated with moral responsibility, it is anger that seems most closely connected with it' $(2001,208)$. If blame is identified with resentment, anger, or indignation and if the kind of moral responsibility at issue in the free will debate is that of deserving blame, then we can frame philosophical issues about moral responsibility in terms of whether or not people ever deserve resentment, anger, or indignation for what they do.

Supposing this is the correct way of framing the debate about moral responsibility, ${ }^{1}$ what features do emotions have that explain people's deservingness of them? My aim in this paper is to answer this question by presenting a sketch of three functions of reactive emotions that plausibly ground claims of their desert. I largely focus on negative emotions

*Email: zcogley@nmu.edu 
like resentment, anger, and indignation because these have been most discussed in the literature. However, I believe my analysis also applies to candidate positive emotions like gratitude.

\title{
1.2. Case study
}

As a way of drawing out our intuitive sense that someone can deserve resentment, anger, or indignation for what she does, consider this fictional anecdote:

\begin{abstract}
You submitted your tenure documents early, thinking everything is in good order. One day, however, you receive an email from the dean inviting you to a meeting. The dean tells you that while the departmental evaluation as a whole was excellent, one of your colleagues has independently written against your promotion with numerous allegations: plagiarism, failing to hold required office hours, and even copying lecture notes from Wikipedia.
\end{abstract}

You explain to the dean that all of the allegations are baseless. She is supportive and suggests you to submit a letter of response within a week. While you write the letter, you seethe with resentment thinking about the colleague who tried to sabotage your promotion. You suspect this is retaliation for some of your justified (but unpopular) stances in recent department meetings. And there's no question who it is - Jesse, an ethicist with whom you've butted heads in the past.

When we think about this example involving your colleague Jesse, it seems intuitive that - other things being equal - he deserves your resentment because of what he did. Other things might not be equal, of course. Jesse might be a psychopath or might have been manipulated to falsely accuse you by a team of nefarious neuroscientists. Much debate about moral responsibility concerns whether or not such conditions impact someone's deservingness of resentment. In what follows, I mostly set these types of situations aside in the interest of offering an account of the features of reactive emotions that ground people's deservingness of them (though I briefly discuss the theory's import for such issues at the end of the paper). My aim is to offer a theory of desert of emotions that can account for our intuition that someone can deserve resentment just because of what they did.

\subsection{Initial proposal}

To say a reactive emotion is deserved simply because of what the person did means that the attitude is appropriate in some sense simply in virtue of what the person did (Feinberg 1970; Miller 1999). I suggest we can unpack the relevant sorts of appropriateness by attending to the multiple psychological functions of the reactive emotions: appraisal, communication, and sanction. Better understanding of the psychological functions of the reactive emotions will in turn help elucidate their moral aims. And in understanding the moral roles they play, we will be helpfully guided by other sorts of things people can deserve - grades, replies, and sanctions - and their corresponding aims. My argument relies on the methodological assumption that we can understand the desert of reactive emotions by analogy with these other things which can be deserved. We primarily take grades to be deserved in virtue of their appraising role, replies to be deserved in virtue of their role in communication, and sanctions to be deserved in virtue of marking acts of wrongdoing as such. The basic desert of reactive emotions involves these same three related, but distinct, moral aims: appraisal, communication, and sanction. ${ }^{2}$ My analysis helps us 
to understand the distinct claims of desert, as opposed to other moral considerations that may apply to reactive emotions.

\section{Desert and appraisal}

\subsection{Appraisal}

Imagine that you are grading papers and arrive at a paper from one of your most promising students. Delighted to read something better than the average essay, you excitedly begin to pore over the paper. Your excitement quickly turns to chagrin, however; the paper shows significant confusion about the topic and does not manage to develop a coherent thesis. The writing is too hurried and there are numerous grammatical mistakes. You reluctantly think to yourself, "I was expecting to give this paper an "A", but I guess it only deserves a " $C$ ".' What underlies your thought that the paper does not deserve an 'A' but does deserve a ' $\mathrm{C}$ ' is that the aim of grading is to accurately reflect the quality of student work. The grade you assign serves as an evaluation, or, we might say, an appraisal, of your student's performance. Appraisals, then, are representations or evaluations of particular states of affairs.

A similar observation connecting appraisal and desert applies to the reactive emotions. Return to the above story about your diabolical colleague who appears to be trying to sabotage your promotion out of ill will. There is an obvious sense in which, if you are going to feel any emotion toward your colleague at all, it is resentment he deserves. Our sense that Jesse deserves reactive emotions like resentment, anger, and indignation in virtue of their role in appraising his conduct is supported by psychological research investigating the connection of emotions to characteristic appraisals.

For example, James Averill claims that 'more than anything else, anger is an attribution of blame' $(1983,1150)$ and Shaver et al. argue that anger appraises a situation as 'illegitimate, wrong, unfair, contrary to what ought to be' $(1987,1078)$. Extrapolating from these observations, I suggest the core appraisal of anger, resentment, and indignation is of someone's conduct as wrongful. To feel one of these emotions is to represent the world as containing a person and her action, and to evaluate that action as wrong because it is done out of ill will or because the person showed insufficient moral concern. For ease of expression below, I often omit mention of ill will and insufficient concern as elements of resentment's appraisal, but my use of 'wrongful conduct' should be read as including them.

\subsection{Transparency and the aim of appraising}

We are now in a better position to explain why it is intuitive that if someone does something wrong out of ill will, she deserves resentment just because of what she did. We can make sense of this idea by appealing to the conceptual connection between emotion and appraisal. It is clear that your colleague Jesse deserves your resentment just because he tried to sabotage your tenure since your resentment accurately appraises what he did. Consider an analogy from philosophical work on belief: from the first person perspective, the question of whether to believe that $P$ appears to collapse into the question of whether $P$ is true. Following Richard Moran, let us call this phenomenon transparency (1988). Nishi Shah (2003) argues that the best account of transparency is that possessing the concept of belief requires accepting the prescription: 'believe $\mathrm{P}$ only if $\mathrm{P}$ is true'. Call truth, then, belief's characteristic aim. Returning to the example of your colleague, suppose a friend asks you why he should believe that Jesse is the one attempting the sabotage. You will be able to give 
him compelling reason to form the belief if you can demonstrate that it is true that Jesse is the culprit.

A comparable claim is true about Jesse's deservingness of your resentment. The invocation that Jesse deserves resentment just because he has tried to sabotage your promotion is analogous to the claim that you should believe that Jesse is out to get you just because it is true that he is out to get you. The question of whether someone deserves a reactive emotion appears to collapse into the question of whether or not the emotion's appraisal is accurate in much the same way that the question of whether to believe $P$ collapses into the question of whether $P$ is true.

I am suggesting that emotions have an analogous characteristic aim, 'feel emotion E only if $\mathrm{E}$ is accurate', to the characteristic aim of belief: 'believe $\mathrm{P}$ only if $\mathrm{P}$ is true', and that this helps us to understand why someone can deserve a reactive emotion just because she did something wrong out of ill will. If she did something wrong out of ill will, then feeling resentful about what she did accurately appraises her conduct. Thus, whether resentment is deserved (in this sense) is determined solely by whether resentment is accurate. ${ }^{3}$

Accuracy is determined not only by a match between resentment and the conduct in question, but also by a match between the amount of resentment and the severity of the wrong. Therefore when your reflections on what he did make it obvious that Jesse deserves your resentment, the obviousness of his deserving resentment can be captured by the thought that resentment is an accurate appraisal of what he did. Because other candidate reactive emotions, like gratitude, would inaccurately appraise your colleague's conduct, he is not deserving of those attitudes. Finally, the amount of resentment Jesse deserves is roughly proportionate to the seriousness of the wrong he committed. Because he is done such a fiendish thing, he deserves a significant amount of resentment. ${ }^{4}$

\section{Desert and communication}

\subsection{Communication}

Imagine you are walking downtown in an unfamiliar city. You are at a conference and you have taken the morning off in order to go sightseeing. Having seen all you can in the allotted time, you decide to return to the conference hotel. Unfortunately, you have wandered further than you thought and cannot seem to orient successfully; somehow you have drifted outside of the confines of your map (and, of course, your smart phone will not connect to the Internet). You decide your best shot is to rely on the kindness of a stranger. You ask a man slowly riding by on his bike if he knows the way to the convention center hotel. He replies that he does, so you ask if he can direct you. His response is surprising: 'Wait, you're trying to get to the philosophy conference, aren't you? I recommend you do something else - those people are boring!' He then rides away. Indignantly, you cast about for someone else to ask, all the while thinking 'What a jerk. Even if it's true that we're boring, that wasn't the answer I deserved.'

The thought that you deserved directions to the hotel as an answer to your question can be unpacked by noting that your utterance had a particular aim: the answer to the question you asked. If the biker had responded, 'Sure, head south 10 blocks and then turn left at the river; you can't miss it,' he would have moved the conversation along in the way that your question requested. Similarly, consider the invitation, 'Would you be interested in having lunch with me this week?' If your interlocutor continues the conversation in the way prompted by the question, she will likely say 'Sure', or 'Let's go to the new restaurant 
on Main,' rather than 'Eating too many refined carbs has been shown to cause weight gain!' The latter claim, even if true and helpful, does not count as moving along the conversation in the way requested by the invitation.

These two examples highlight the fact that different utterances have different communicative aims and that what counts as appropriately furthering the conversation depends on the aims of the conversation. There is a suggestive parallel here with H.P. Grice's thought that conversation has normative principles governing appropriate responses, such as 'be relevant', which the biker violates $(1975,46)$. The force of such principles can be overridden, of course, but that is also a feature of desert claims, which are generally thought to carry pro tanto, but not overriding, normative weight. Further, the normative force of such principles would not appear to be easily accounted for by consequentialist or contractual considerations. Suppose you take the biker's recommendation and do something else instead of returning to the conference. Even if you agree that his actual response had better consequences than the return directions would, you might legitimately feel put out that he was not willing to answer your question. After all, he could have answered it as well as recommending against returning to the conference.

These ideas suggest that the internal aims of some types of conversation may help us understand another sense in which reactive emotions are deserved, as there is evidence that reactive emotions also play a communicative function, though one dissimilar to that of an answer to a question. ${ }^{5}$ For example, anger is associated with specific postures (Wallbott 1998), speech patterns (Scherer 1986; Scherer et al. 1991), and facial expressions (Ekman 1999). These features are interpreted by others as conveying anger's characteristic appraisal, as well as intentions or requests (Horstmann 2003). In one case, my posture and speech might indicate that I am ready to strike out at another person. In other cases what is communicated by a reactive emotion might be no such thing. Thus, depending on the case, there are a number of different things that reactive emotions could communicate. We need an account of what they essentially communicate in order to articulate the communicative sense in which your colleague deserves resentment for his actions.

\subsection{The aim of communication}

It is evident that reactive emotions do not aim at furthering communication like questions or invitations (the examples discussed above). We can fix on their communicative aim by articulating the response at which they aim. ${ }^{6}$ The consensus view (Walker 2006; Darwall 2006; Smith 2007; Shoemaker 2007) about the targeted response is described by Colleen Macnamara as acknowledging fault:

the response sought by the expressed negative blaming attitudes includes both emotional and behavioral recognition of wrongdoing, and - more specifically - the target feeling guilt or remorse and expressing it via apology, amends, and the like. (Macnamara, forthcoming, 7)

Both the emotional and behavioral recognition of wrongdoing are essential to complete acknowledgement of fault. An expression of apology or an attempt at amends without feelings of guilt or remorse is insincere; failure to explicitly apologize or make amends leaves flawed conduct inwardly recognized as faulty but fails to give interpersonal recognition to that fact. Notably, recent psychological research provides some support for these theses. Apologizing or making amends without feeling guilt is insincere because anticipated guilt (at the thought of performing similar conduct) is an important mechanism in preventing people from performing socially undesirable actions. If someone makes amends while 
not feeling guilty, he will lack an important psychological factor motivating him not to perform that sort of action in the future. Thus, lack of guilt is a particularly salient indication of the wrongdoer's evaluation of her present and future conduct and whether she repudiates it, or not. For guilt to 'work', 'all the guilt [has] to do ... [is] signal "bad idea" to make the person avoid the tainted course of action' (Baumeister, Vohs, and Nathan DeWall 2007, 173). And, in sympathy with the philosophical commentators above, these psychologists hypothesize that one important function of anger is to cause the target of the emotion to feel guilt $(2007,189)$.

\subsection{What kind of speech act?}

If the conversational aim of the negative-reactive emotions is to get the wrongdoer to acknowledge fault, what does that tell us about the kind of speech act to which reactive emotions are analogous? Steven Darwall $(2006,2010)$ has explored the connection of reactive emotions to speech acts in the most depth, arguing that the blaming attitudes are analogous to demands. ${ }^{7}$ As Macnamara notes, there are two theories Darwall suggests regarding the distinctive conversational content of blaming attitudes construed as demands.

One account sees resentment as demanding that the person not violate a moral obligation. Therefore if you were to feel resentment toward Jesse, it would express to him the demand 'Do not impair the professional development of your colleagues for spurious reasons!' But this is not a good gloss on the communicative content of resentment, as resentment looks backward to the wrong he already committed, not forward to what he might or might not do in the future. Even if he governs his future behavior in accord with this demand, he will not have responded to your resentment in the way that it seeks. Another account of the demand of resentment suggested by Darwall is that it is a demand that Jesse truly acknowledge fault by feeling guilty and expressing it. But as Macnamara points out, this is not a sensible demand to make of someone, for we cannot feel emotions when commanded to do so by others. Not only that, but you do not just want Jesse to feel guilty. You want him to feel guilty because he shares your appraisal of his action as wrongful. ${ }^{8}$

We can account for this idea by following Macnamara in thinking of the negative blaming attitudes as recognitives - speech acts that recognize people in a particular way and seek that the target of the speech act acknowledge she has been recognized in that way. Our default greeting is a recognitive. When I say 'Hi Amanda' to my dean, I recognize her as Amanda. My hail seeks that she acknowledges the greeting by expressing that she has been appropriately recognized. She might smile, wave, say 'Hi' in response, etc. My hail is successful if she does so. Similarly, seeing your resentment of Jesse as a recognitive implies that your resentment construes him as having done something wrong in his attempt to scuttle my promotion and seeks that he see his own behavior as wrongful and give expression to that fact. Resentment and the other negative-reactive emotions thus serve to discursively recognize other people as having done wrong and seek the target's acknowledgement of themselves as having done so. This makes better sense of the idea that the negative-reactive emotions aim at getting wrongdoers to acknowledge fault.

\subsection{Discursively deserving resentment}

Seeing resentment as communicative allows us to understand another sense in which resentment is deserved that is linked to the appraisal sense of desert. Negative-reactive emotions aim at expressing to their targets that they are being appraised in a particular manner. If 
Jesse really has egregiously wronged you, then your resentment of him accurately appraises him and aims to communicate to him that you have done so. If he thereby comes to recognize himself as having acting wrongfully and acknowledges fault, your resentment will have been successful. However, resentment need not be successful to be deserved. For it to be deserved in the communicative sense is for it to fulfill an appropriate conversational aim, which is trying to communicate your appraisal of his action to Jesse, with the hope that he will come to share it.

It might be objected that we typically do not think that communication needs to be possible in order to think that someone is deserving of resentment. ${ }^{9}$ After all, if right after you learn what Jesse did, he dies, or flees the country, or simply vanishes forever, you will never have any chance of communicating to him, but your sense that he deserves your resentment will not disappear - and may even increase. However, these facts are actually evidence in favor of the idea that resentment aims at communication. Evidence suggests that both online disputes (Wolchover and Life's Little Mysteries 2012) ${ }^{10}$ and disputes with other drivers while driving (Parkinson 2001) generate greater resentment than do face-to-face encounters because effective communication is denied. It is precisely in environments where the possibility of communication - and so any response by the perceived wrongdoer - is cut off that resentment is most likely to flourish. Even if you know that successful communication - in the form of getting the target to appraise herself as a wrongdoer - is impossible, your resentment of her still aims at communication.

Here I have been discussing a communicative function of emotions that I believe can also help explicate how someone can deserve an emotion like resentment. People deserve different communicative responses depending on the conversations and conduct in which they engage. While the communicative sense of desert is distinct from the appraisal sense, it similarly accounts for the idea that someone can deserve resentment just because her conduct was wrongful. When you think someone wrongs you, the communicatively appropriate response is to notify her that you have appraised her behavior in that way and urge her to share that assessment of what she has done. Thus, resentment is also deserved qua communication just because the person did something wrongful. ${ }^{11}$

\section{Desert and sanction}

\subsection{Sanction}

Suppose you have agreed to watch the children of a single colleague while he is away giving a paper at a conference. Your colleague warned you that his children are at an 'acting out' stage. Sure enough, on the second day you are watching them, the 9-yearold, Sam, hits her 8-year-old brother, Andre, hard enough to leave a bruise. While Andre played a role in the altercation, Sam is old enough to know better than to hit someone (except in self-defense!). Your colleague gave you permission to discipline the children if they acted badly, so you tell Sam that if she hits her brother again she will have to spend some time alone in her room. About an hour later there is another altercation and, sure enough, Sam hits Andre, so you send her to her room. The next day your colleague comes home; Sam runs to him to complain about what she regards as her unfair treatment. After hearing from her what happened, your colleague says, 'Well Sam, it sounds like you deserved to be sent to your room!'

This vignette involves another type of thing that can be deserved: a sanction. Sanctions are penalties for violating a requirement or obligation. (The requirement or obligation is often a moral one, but it need not be.) There is much psychological evidence that people 
feeling negative-reactive emotions are prone to engage in acts that have the effect of sanctioning others (Pillutla and Murnighan 1996; Lerner, Goldberg, and Tetlock 1998). But even apart from actions that angry people may take, expressed reactive emotions themselves have a sanctioning function. As previously noted, some psychologists have suggested that reactive emotions may function to cause guilt in their target (Baumeister, Vohs, and Nathan DeWall 2007). It is also plausible that it is unpleasant in its own right to be the target of another person's resentment. This unpleasantness means that expressed reactive emotions are themselves sanctions for wrongful acts.

\subsection{The sanction of resentment}

I think we can also articulate someone's deservingness of reactive emotions by appeal to their sanctioning function. To see this, suppose that instead of sending Sam to her room because she hit her brother, you sent her to her room for helping to clear the table after dinner. (You are tired and you feel annoyed that she thought you would need help cleaning up.) Sam's punishment in this case is not deserved because sending her to her room implies that she did something wrong, but she did not do anything wrong in helping to clear the table. By sending her to her room for helping clear the table you incorrectly appraise her act as wrongful and this makes the punishment undeserved. Punishing an act implies it has been appraised as wrongful; if it is not wrongful then the punishment is undeserved. Similarly, suppose that rather than send Sam to her room for helping to clear the table you do so because she burps during dinner - a minor breach of etiquette. While it might be appropriate to correct the breach of decorum, sending her to her room suggests that she did something more seriously wrong, when she did not. Other things equal, then, in order to be deserved, the severity of the punishment should be roughly proportionate to the wrong the person does. ${ }^{12}$ If not, the punishment is an unfitting appraisal of the act.

However, Sam's punishment for helping to clear the table is not just undeserved because the punishment implies, falsely, that her conduct is wrongful. Sam's punishment is also undeserved because sending her to her room communicates to her that she should see herself as a wrongdoer. The punishment implicitly demands that she acknowledge fault for what she did; that is, feel guilty because she sees her act as wrongful and express her guilt via apology or amends. It thus demands of her that she see her act in an unfitting way and express this erroneous appraisal to you. But the discursively appropriate response for Sam is something along the lines of, 'Why are you sending me to my room for doing something nice?' not 'I'm sorry I helped to clear the table.'

I want to suggest that harmful or unwanted treatment counts as a punishment ${ }^{13}$ in virtue of it playing both the appraising and communicative roles. If it properly plays those roles, then the harmful treatment is deserved. If it plays those roles improperly, it is an undeserved punishment. ${ }^{14}$ And if a wrongdoer undergoes harm that does not play those roles at all, the wrongdoer not only fails to get what she deserves, but she also is not punished. Return now to the case where Sam hits her brother after you have warned her that she will be sent to her room if she hits him again. Before you have the chance to punish her, Sam goes into her room and closes the door, which sticks shut. After tending to her brother you get an important phone call and forget entirely about punishing Sam. Sam remains stuck in her room for the same amount of time that she would have spent there in time-out and she finds it unpleasant because all of the things she wants to do are in the other room. In this case, Sam undergoes a harm that follows her wrongful act. But because that harm did not play any role in appraising or communicating the wrongfulness of what she did, Sam fails to be punished and fails to get what she deserves. 
The point of this example is to demonstrate that even if Sam undergoes the same harm or cost as she would have in being punished, the imposition of that cost does not count as punishment unless it serves the dual aims of appraisal and communication. Thus, as a conceptual matter, punishment has both these internal aims, though neither aim has to be successful in order for the punishment to be deserved. For example, Sam's refusal to agree that her act was wrong does not count against her deservingness of punishment for it. The point of punishment is to attempt to publicly mark actions as wrongful and to attempt to communicate to wrongdoers that they ought to share that appraisal.

\subsection{Deserving the reactive emotions vs. the reactive emotions being justified}

So far I have argued that a sanction is an unwanted or harmful treatment that plays the dual roles of negatively appraising and communicating that appraisal to others. And sanctions are deserved just in case they properly play the appraisal and communicative roles in a way roughly proportionate to the seriousness of the wrong done. In this section, I want to distinguish a person's deserving the sanction of the reactive emotions from some other questions that bear on their overall justification. My aim here is to help support the idea that the appraisal, communicative, and sanctioning functions distinguish someone's deservingness of a reactive emotion from other normative claims that bear on the justification of reactive emotions.

The first factor relevant to justification but not desert is the question of proper standing, or authority. ${ }^{15}$ Return to the case where Sam hits her brother. Suppose this time that you observe the event at your colleague's house while he is at home. Wanting to help your colleague, you send Sam to her room. This constitutes a clear overstepping of familial boundaries. Since you are not baby-sitting and have not been granted authority to punish Sam, you are required to inform your colleague about Sam's behavior and allow him to choose whether or not to punish her. Your punishment of Sam is unjustified. She does, however, deserve to be punished in the same way she would if her own parent had imposed it because the punishment plays the joint aims of appraisal and communication.

In this example, another factor, proper authority, bears on the justification of Sam's punishment but not on her deservingness of it. Similarly, lack of authority can also affect the justification of someone's expression of a reactive emotion even though it does not bear on whether or not she expressed a reactive emotion that is deserved by its target. Imagine your dean is gossiping to her neighbor about what Jesse did to you. The neighbor becomes incensed and later storms over to the university, bursts into Jesse's office, and expresses his resentment in a manner loud enough for the rest of the department to hear. You are justifiably infuriated at this imposition. You would prefer to have the matter die a quiet death without members of the community becoming involved. The dean's neighbor lacks proper authority to sanction Jesse, even though Jesse gets what he deserves in the form of the expression of a reactive emotion. ${ }^{16}$

Let us return to Sam again to see another factor that can impact the justification of a sanction but not whether it is deserved. Once again, Sam hits her brother while you are baby-sitting so there is no question that you have the authority to punish her. You are about to send her to her room for time-out when you remember that your colleague also instructed you that Sam needs to help her brother with his book report that is due the next day. The computer that Andre needs to work on is in the living room; Sam obviously will not be able to assist if you send her to her room. Realizing that completing the assignment is more important than giving Sam what she deserves, you allow her to stay in the living room on the condition that she help her brother with the book report. 
In this case, the cost of giving Sam what she deserves is high enough that the best thing to do is to not give it to her. In a comparable manner, the costs imposed by the sanctioning function of the reactive emotions can mean that a deservingly expressed reactive emotion would be unjustified. To see this, suppose that shortly after Jesse tries to hurt your tenure case, you learn that he was denied tenure at his previous institution. This fostered a sense of diminished worth in him and he tries to compensate by ensuring that he is not shown up professionally. Further, you learn that Jesse's anguish over his denied tenure has developed into full-blown depression, which has led him to contemplate suicide on more than one occasion. Learning these facts changes your feelings about the justification of expressing your resentment toward him. You realize that the negative feelings (shame, guilt) in Jesse that could result from showing your resentment could push him into a suicide attempt. ${ }^{17}$ Even though (we can suppose) he is still deserving of your expressed resentment, you try to hide it in your dealings with him. While an expression of resentment would still be deserved by Jesse, the costs of expression are high enough that they make expressing a reactive emotion unjustified.

\section{Conclusion}

These previous sections presented examples that highlight that the appraisal, communication, and sanction functions of resentment uniquely differentiate the factors that bear on a person's deservingness of resentment from other factors that might affect the overall justification of feeling such an emotion. I have thus argued that we can make sense of the deservingness of emotions like resentment by articulating their three-fold moral aims: appraisal, communication, and sanction. When resentment properly serves these aims it is deserved in the basic sense. Thus, other things equal, resentment is deserved when felt toward someone who acts wrongfully because she is motivated by ill will (or fails to have sufficient moral concern) and the amount of resentment is roughly proportionate to the severity of the transgression. This account articulates why your colleague Jesse is deserving of your resentment for his despicable actions. Feeling significant resentment toward him accurately appraises him as a wrongdoer, communicates that fact to him, and harms him in the way distinctive of expressed negative moral appraisals. Because your resentment is accurate, communicatively appropriate, and harms him in the service of those two aims, it is deserved.

This account helpfully unpacks the thought that someone can deserve negative-reactive emotions like resentment just because she did something wrong. My hope is that articulating this thought in terms of appraisal, communication, and sanction will aid future philosophical work on desert and moral responsibility. More work remains to be done, of course. One important question that remains to be investigated is whether it is possible for an emotion to be deserved in only one or two senses but not the others and, if so, how that matters for our understanding of emotional desert and moral responsibility.

It might be that there are other ways to account for the intuitive idea that someone deserves emotions like resentment simply in virtue of doing something wrong. I have provided no argument against other potential approaches (however, am I not aware of any competitors), nor have I provided an argument against the idea that claims about emotional desert are basic in the sense that they cannot be further explained at all. Still, the theory has promise for its ability to account for our intuitive sense that a person who does wrong out of ill will deserves resentment just because of what she did. Similarly, the theory correctly implies that a person innocent of wrongdoing does not deserve resentment or other reactive emotions. The reasons such attitudes are undeserved by the innocent concerns the fact that they would be inaccurate appraisals, inappropriate communications, and 
unmerited sanctions. These moral aims are perverted in a situation where we resent the innocent, even if resenting brings about the best outcome.

Finally, I hope that the theory will have application to contentious debates about moral responsibility, such as whether psychopaths are morally responsible for wrongs they commit and whether people who are manipulated into doing wrong can be morally responsible for their manipulated actions. If I am right that people deserve resentment in virtue of it appropriately fulfilling the aims of appraisal, communication, and sanction, we may make progress on contentious issues about responsibility by investigating whether such aims make sense in reference to psychopaths or manipulated persons. With an account of what it is to deserve reactive emotions, we may be better able to see whether such conditions undermine people's moral responsibility.

\section{Acknowledgements}

I very much appreciate the help of Andrea Scarpino, Antony Aumann, Randolph Clarke, and David Morrow, who all provided valuable comments on drafts of this manuscript. An audience at Loyola University, New Orleans also gave instructive feedback. Finally, many thanks to the two anonymous referees whose comments aided in substantially improving the paper.

\section{Notes}

1. Not all would agree that it is, either because they do not put desert in a central role or think the nature of blame is different. Prominent examples of the latter include Sher (2006) and Scanlon (2008).

2. In my paper 'The Three-Fold Significance of the Reactive Emotions' I propose that anger, resentment, and indignation have three psychological functions: appraisal, communication, and sanction, and I show that different accounts of moral responsibility can be understood as implicitly invoking various of these senses. When writing that paper, I did not yet appreciate that each of the psychological functions can itself serve a legitimate moral aim connected to desert. My aim in this paper is to make that case.

3. Compare Justin D'Arms and Daniel Jacobson on what they term the fittingness of emotions (2000).

4. It might be thought that explicating desert of emotions in terms of accurate appraisal has the surprising result that inanimate things can deserve. For example, excitement seems like the fitting response when you get the news that you won the lottery. Therefore is it problematic that my account suggests that things like news can be deserving? I think it is not. First, my theory does not imply that anger, resentment, or indignation can be deserved by even very bad news. News cannot engage in wrongful conduct, which is what I argue makes resentment deserved. Also, we often speak of things that are not agents being deserving, as in 'the Grand Canyon deserves to be admired' and 'the painting deserves praise'. It is possible that such claims invoke a notion of desert other than the one at issue here, but I think it is a felicitous result that my theory can account for such uses. Further, nothing in my theory implies that the features of a painting which deserve praise must be exactly the same as the features of people who are deserving of it. (I thank an anonymous referee for raising this issue.)

5. In his new book, Conversation and Responsibility, Michael McKenna argues that a person's actions can be seen as the initiation of a conversation to which others may reply by having reactive emotions or blaming (2012). I am not sure whether I am convinced that actions themselves should be seen as conversational moves. However, I am in agreement that the feeling of a reactive emotion toward someone is conversational.

6. My discussion in the next two sections is indebted to (Macnamara, forthcoming).

7. Others have also connected the reactive emotions and demands (Strawson 1982; Watson 1993; Wallace 2008) but Darwall distinctively construes demands as analogous to speech acts.

8. For further discussion of these points, see Section 4 of Macnamara (forthcoming).

9. I thank an anonymous reviewer for raising this point.

10. Apparently, 'Life's Little Mysteries' is really the co-author's name.

11. It might be objected that someone deserving resentment for doing something wrong is just different from the sense in which a person deserves directions in virtue of asking for them. 
In response, it is important that my account does not imply deserving resentment is exactly the same as deserving the answer to a question. Rather, the example helps to elucidate the idea that our communications with each other are guided by norms that do not directly appeal to consequentialist or contractual considerations. All I claim is that resentment has a communicative aim, not that it has exactly the same sort of communicative aim that all the conversational examples do. (I thank an anonymous reviewer for raising this issue.)

12. Saying just what conditions constitute satisfaction of the proportionality calculus is complicated. I leave it as intuitive that proportionality matters; how to cash this out deserves additional attention in another forum.

13. While there is a vast literature on the deservingness of state punishment, cases of interpersonal punishment are more directly analogous to the blaming attitudes. For a comprehensive and critical discussion of whether state punishment can be justified by the deservingness of wrongdoers, see Dolinko (1991a, 1991b).

14. I do not have a theory to offer here about how a harmful or unwanted treatment comes to fulfill these roles and so counts as a punishment. This claim also deserves additional attention in further work.

15. For more on the notion of proper standing, or authority, to blame see Cohen (2006) and Smith (2007).

16. For concurrence on this point, see Feinberg (1970) and Olsaretti (2003), who claim that the facts relevant to someone's desert exclusively concern facts about that person, not relational ones.

17. Roy Baumeister's (1990) account of suicidal motivations supports the possibility of such a reaction. I mean to assume that Jesse's depression does not undermine his responsibility for attempting to sabotage your tenure case.

\section{Notes on contributor}

Zac Cogley is an Assistant Professor at Northern Michigan University. Prior to coming to Northern Michigan University, he taught at University of California, Los Angeles and received his $\mathrm{PhD}$ from The Ohio State University. His interests are in ethics, agency theory, moral responsibility, and emotion.

\section{References}

Averill, James R. 1983. Studies on anger and aggression: Implications for theories of emotion. American Psychologist 38, no. 11: 1145-60.

Baumeister, Roy F. 1990. Suicide as escape from self. Psychological Review 97, no. 1: 90-113.

Baumeister, Roy, K.D. Vohs, and C. Nathan DeWall. 2007. How emotion shapes behavior: Feedback, anticipation, and reflection, rather than direct causation. Personality and Social Psychology Review 11, no. 2: 167-203.

Bennett, Christopher. 2002. The varieties of retributive experience. The Philosophical Quarterly 52, no. 207: $145-63$.

Cohen, G.A. 2006. Casting the first stone: Who can, and who can't, condemn the terrorists? Royal Institute of Philosophy Supplement 58: 113-36.

D'Arms, Justin, and Daniel Jacobson. 2000. The moralistic fallacy: On the 'Appropriateness' of emotions. Philosophy and Phenomenological Research 61, no. 1: 65-90.

Darwall, Stephen. 2006. The second-person standpoint: Morality, respect, and accountability. Cambridge, MA: Harvard University Press.

Darwall, Stephen. 2010. Justice and retaliation. Philosophical Papers 39, no. 3: 315-41.

Dolinko, David. 1991a. Three mistakes of retributivism. UCLA Law Review 39: 1623.

Dolinko, David. 1991b. Some thoughts about retributivism. Ethics 101, no. 3: 537-59.

Ekman, Paul. 1999. Basic emotions. In Handbook of cognition and emotion, ed. Tim Dalgleish and Mick Power, 45-60. New York: Wiley.

Feinberg, Joel. 1970. Justice and personal desert. In Doing and deserving: Essays in the theory of responsibility, 55-94. Princeton: Princeton University Press.

Grice, H.P. 1975. Logic and conversation. In Syntax and semantics 3: Speech arts, ed. Peter Cole and Jerry L. Morgan, 41-58. New York: Academic Press.

Horstmann, Gernot. 2003. What do facial expressions convey: Feeling states, behavioral intentions, or actions requests? Emotion 3, no. 2: 150-66. 
Lerner, Jennifer S., Julie H. Goldberg, and Philip E. Tetlock. 1998. Sober second thought: The effects of accountability, anger, and authoritarianism on attributions of responsibility. Personality and Social Psychology Bulletin 24, no. 6: 563-74.

Macnamara, Coleen. Forthcoming. 'Screw you!' \& 'Thank you'. Philosophical Studies 1-22. http:// link.springer.com/article/10.1007/s11098-012-9995-3.

McKenna, Michael. 2012. Conversation and responsibility. New York: Oxford University Press.

Miller, David. 1999. Deserts. In What do we deserve?, ed. Louis Pojman and Owen McLeod, 93-100. Oxford: Oxford University Press.

Moran, Richard. 1988. Making up your mind. Ratio 1, no. 2: 135-51.

Olsaretti, Serena. 2003. Introduction: Debating desert and justice. In Desert and justice, ed. Serena Olsaretti, 1-24. New York: Oxford University Press.

Parkinson, Brian. 2001. Anger on and off the road. British Journal of Psychology 92, no. 3: 507-26.

Pereboom, Derk. 2001. Living without free will. Cambridge: Cambridge University Press.

Pereboom, Derk. 2008. A hard-line reply to the multiple-case manipulation argument. Philosophy and Phenomenological Research 77, no. 1: 160-70.

Pillutla, Madan M., and J. Keith Murnighan. 1996. Unfairness, anger, and spite: Emotional rejections of ultimatum offers. Organizational Behavior and Human Decision Processes 68, no. 3: 208-24.

Scanlon, T.M. 2008. Moral dimensions: Permissibility, meaning, blame. Cambridge, MA: Belknap Press of Harvard University Press.

Scherer, K.R. 1986. Vocal affect expression: A review and a model for future research. Psychological Bulletin 99, no. 2: 143-65.

Scherer, K.R., R. Banse, H.G. Wallbott, and T. Goldbeck. 1991. Vocal cues in emotion encoding and decoding. Motivation and Emotion 15, no. 2: 123-48.

Shah, Nishi. 2003. How truth governs belief. The Philosophical Review 112, no. 4: 447-82.

Shaver, P., J. Schwartz, D. Kirson, and C. O’Connor. 1987. Emotion knowledge: Further exploration of a prototype approach. Journal of Personality and Social Psychology 52, no. 6: 1061-86.

Sher, George. 2006. In praise of blame. New York: Oxford University Press.

Shoemaker, David. 2007. Moral address, moral responsibility, and the boundaries of the moral community. Ethics 118, no. 1: 70-108.

Smith, Angela M. 2007. On being responsible and holding responsible. The Journal of Ethics 11: $465-84$.

Sommers, Tamler. 2007. The objective attitude. The Philosophical Quarterly 57: 321-41.

Strawson, Galen. 2002. The bounds of freedom. In The Oxford handbook of free will, ed. Robert Kane, 441-60. New York: Oxford University Press.

Strawson, P.F. 1982. Freedom and resentment. In Free will, ed. Gary Watson, 59-80. Oxford: Oxford University Press.

Walker, Margaret. 2006. Moral repair. Cambridge: Cambridge University Press.

Wallace, R. Jay 1994. Responsibility and the moral sentiments. Cambridge, MA: Harvard University Press.

Wallace, R. Jay 2008. Emotions, expectations, and responsibility. In Free will and reactive attitudes, ed. Michael McKenna and Paul Russell, 157-85. Surrey, UK: Ashgate.

Wallace, R. Jay 2011. Dispassionate opprobrium: On blame and the reactive sentiments. In Reasons and recognition. Essays on the philosophy of T. M. Scanlon, ed. R. Jay Wallace, Rahul Kumar and Samuel Freeman, 348-72. New York: Oxford University Press.

Wallbott, Harald. 1998. Bodily expression of emotion. European Journal of Social Psychology 28, no. 6: $879-96$.

Watson, Gary. 1993. Responsibility and the limits of evil: Variations on a Strawsonian theme. In Perspectives on moral responsibility, ed. John Martin Fischer and Mark Ravizza, 119-50. Ithaca, NY: Cornell University Press.

Wolchover, Natalie, and Life's Little Mysteries. 2012. Why is everyone on the internet so angry? Scientific American. July 25. http://www.scientificamerican.com/article.cfm?id=why-iseveryone-on-the-internet-so-angry.

Wolf, Susan. 2011. Blame, Italian style. In Reasons and recognition. Essays on the philosophy of T. M. Scanlon, ed. R. Jay Wallace, Rahul Kumar and Samuel Freeman, 332-47. New York: Oxford University Press.

Zimmerman, Michael J. 1988. An essay on moral responsibility. Totowa, NJ: Rowman \& Littlefield. 